\title{
Sevoflurane versus propofol for interventional neuroradiology: a comparison of the maintenance and recovery profiles at comparable depths of anesthesia
}

\author{
Eun-Su Choi ${ }^{1}$, Ji Yeon Shin ${ }^{2}$, Ah Young Oh ${ }^{1}$, Hee-Pyoung Park ${ }^{2}$, Jung-Won Hwang ${ }^{1}$, Young Jin Lim ${ }^{2}$, \\ and Young-Tae Jeon ${ }^{1}$ \\ Department of Anesthesiology and Pain Medicine, ${ }^{1}$ Seoul National University Bundang Hospital, Seongnam, ${ }^{2}$ Seoul National \\ University Hospital, Seoul, Korea
}

Background: Sevoflurane and propofol are used widely for interventional neuroradiology (INR). Using the bispectral index (BIS), we compared the clinical properties of sevoflurane and propofol anesthesia in patients undergoing INR at comparable depths of anesthesia.

Methods: The patients were allocated randomly into two groups. The sevoflurane group received propofol (1.5 mg/kg), alfentanil $(5 \mu \mathrm{g} / \mathrm{kg})$, and rocuronium $(0.6 \mathrm{mg} / \mathrm{kg})$ for induction, and the propofol group was induced with a target effectsite concentration of propofol $(4 \mu \mathrm{g} / \mathrm{ml})$, alfentanil $(5 \mu \mathrm{g} / \mathrm{kg})$, and rocuronium $(0.6 \mathrm{mg} / \mathrm{kg})$. After intubation, anesthesia was maintained with sevoflurane or propofol with $67 \%$ nitrous oxide in $33 \%$ oxygen. Sevoflurane and propofol concentrations were titrated to maintain the BIS at 50-60. Phenylephrine or opioid was used to maintain the mean arterial pressure within $20 \%$ of the baseline values. The amounts of phenylephrine or alfentanil used, the number of patients showing movement during the procedure, and the recovery times were recorded.

Results: Compared to the propofol group, the sevoflurane group showed faster recovery in spontaneous ventilation, eye opening, extubation, and orientation ( 4 vs. $7 \mathrm{~min}, 7$ vs. $9 \mathrm{~min}, 8$ vs. $10 \mathrm{~min}, 10$ vs. $14 \mathrm{~min}$, respectively; $\mathrm{P}<0.01$ ). In the propofol group, significantly greater amounts phenylephrine were used $(\mathrm{P}<0.05)$, and more patients moved during the procedure $(\mathrm{P}<0.05)$.

Conclusions: The use of sevoflurane in maintaining anesthesia during INR was associated with faster recovery, less patient movement during the procedure, and a more stable hemodynamic response when compared to propofol. (Korean J Anesthesiol 2014; 66: 290-294)

Key Words: Bispectral index, Interventional radiology, Propofol, Sevoflurane.

Received: May 28, 2013. Revised: 1st, July 30, 2013; 2nd, August 29, 2013; 3rd, September 23, 2013; 4th, October 1, 2013. Accepted: October 1, 2013. Corresponding author: Young-Tae Jeon, M.D., Ph.D., Department of Anesthesiology and Pain Medicine, Seoul National University Bundang Hospital, 300, Gumi-dong, Bundang-gu, Seongnam 463-707, Korea. Tel: 82-31-787-7493, Fax: 82-31-787-4063, E-mail: ytjeon@snubh.org (c) This is an open-access article distributed under the terms of the Creative Commons Attribution Non-Commercial License (http:// creativecommons.org/licenses/by-nc/3.0/), which permits unrestricted non-commercial use, distribution, and reproduction in any medium, provided the original work is properly cited. 


\section{Introduction}

General anesthesia is used for immobilizing patients during interventional neuroradiology (INR) procedures to enhance image quality, decrease patient discomfort, and improve control of respiratory and hemodynamic profiles [1-3]. Anesthetic agents such as propofol, sevoflurane, isoflurane, and desflurane are commonly used to maintain anesthesia in patients undergoing general anesthesia for INR [4]. Previous studies have shown that sevoflurane is associated with more rapid recovery than that achieved using propofol, whereas isoflurane and propofol showed similar recovery profiles in patients emerging from anesthesia [5,6]. However, these studies used hemodynamic variables to titrate the depths of anesthesia, and neither movement nor intraoperative awareness can be assessed using hemodynamic indices [7].

The bispectral index (BIS) is used widely to monitor the depth of anesthesia. The use of BIS counters superfluous anesthesia and might result in quicker recovery [8]. In a previous study comparing anesthetic practice with and without BIS titration, the BIS-monitored group showed more rapid recovery from anesthesia with reduced propofol use [9]. BIS is a better predictor of patient response than the hemodynamic status [10].

The present study compared the effectiveness of sevoflurane and propofol in anesthesia maintenance during INR at comparable depths of anesthesia and examined differences in the maintenance and recovery profiles.

\section{Materials and Methods}

With approval from the Institutional Review Board in our hospital, and after obtaining written informed consent, we prospectively studied 66 patients (American Society of Anesthesiologists physical status I-III, ages 18-65 years) who were scheduled for elective INR coiling of unruptured aneurysms. Exclusion criteria included a ruptured aneurysm, history of neurologic disease, alcohol or drug abuse, and preexisting renal or hepatic dysfunction. Using the block randomization technique, the 66 patients were randomly divided into the sevoflurane (n

Table 1. Demographic Data

\begin{tabular}{lcc}
\hline & $\begin{array}{c}\text { Sevoflurane } \\
(\mathrm{n}=33)\end{array}$ & $\begin{array}{c}\text { Propofol } \\
(\mathrm{n}=33)\end{array}$ \\
\hline Age (yr) & $58 \pm 13$ & $60 \pm 11$ \\
Sex $(\mathrm{M} / \mathrm{F})$ & $11 / 22$ & $9 / 24$ \\
Weight $(\mathrm{kg})$ & $64 \pm 10$ & $64 \pm 10$ \\
Height $(\mathrm{cm})$ & $158 \pm 9$ & $160 \pm 9$ \\
Duration of surgery (min) & $71 \pm 36$ & $65 \pm 31$ \\
Duration of anesthesia (min) & $98 \pm 36$ & $89 \pm 31$
\end{tabular}

Values are mean \pm SD.
$=33)$ and propofol $(n=33)$ groups before anesthesia induction. The two groups did not differ in age, sex, weight, height, total procedure time and total anesthetized time (Table 1).

The electrocardiogram, noninvasive arterial blood pressure, pulse oximetry, and capnography were monitored in the neuroradiology suite. We measured the baseline heart rate (HR), peripheral arterial hemoglobin oxygen saturation, mean arterial pressure (MAP) and BIS values.

Midazolam $(0.03 \mathrm{mg} / \mathrm{kg})$ was administered intravenously 15 min before induction. In the sevoflurane group $(\mathrm{n}=33)$, anesthesia was induced by the administration of propofol $(1.5 \mathrm{mg} /$ $\mathrm{kg})$, alfentanil ( $5 \mu \mathrm{g} / \mathrm{kg})$, and rocuronium $(0.6 \mathrm{mg} / \mathrm{kg})$ and maintained with sevoflurane with $67 \%$ nitrous oxide in $33 \%$ oxygen. In the propofol group $(\mathrm{n}=33)$, anesthesia was induced with the target effect-site concentration of $4 \mu \mathrm{g} / \mathrm{ml}$ of propofol, $5 \mu \mathrm{g} / \mathrm{kg}$ of alfentanil, and $0.6 \mathrm{mg} / \mathrm{kg}$ of rocuronium, and anesthesia was maintained with propofol and $67 \%$ nitrous oxide in $33 \%$ oxygen. The concentration of sevoflurane and propofol was adjusted to maintain the BIS at 50-60. In cases of BIS values $<50$ or $>60$, the propofol infusion was adjusted by $0.5 \mu \mathrm{g} / \mathrm{ml}$ target effectsite concentration or the end-expiratory sevoflurane concentration was adjusted by the 0.25 minimum alveolar concentration (MAC).

By administering alfentanil or phenylephrine, we maintained the intraoperative MAP within $20 \%$ of the pre-induction values. The patients' lungs were ventilated to an end-tidal carbon dioxide concentration of 30-35 mmHg. Rocuronium ( $10 \mathrm{mg} / \mathrm{hr}$ ) was continuously infused to maintain muscle relaxation of either zero or one of the train-of-four (TOF) during the procedure using a nerve stimulator.

The anesthetic and rocuronium infusions were stopped at the completion of the coiling procedure. Immediately after stopping rocuronium infusion, muscle relaxation of one TOF was confirmed by nerve stimulation, and any residual neuromuscular blockage was reversed with neostigmine and glycopyrrolate. The lungs were ventilated with $100 \%$ oxygen at a fresh gas flow rate of $10 \mathrm{~L} / \mathrm{min}$ for both groups. The same minute ventilation was maintained during the procedure. No cases showed hyperor hypoventilation. In each patient, extubation was performed when all the following requirements were met: adequate airway reflexes, open eyes, a minimum TOF ratio of 0.9 , and adequate spontaneous breathing. The following recovery times were evaluated at $60 \mathrm{sec}$ intervals by an observer who was blinded to the type of maintenance anesthesia: time of return to spontaneous ventilation, time to eye opening, time to extubation, and time to orientation (correctly answering the question, "What is your name?"). Additionally, the amounts of phenylephrine or alfentanil were recorded. Patient movements that might have interrupted the procedure were recorded.

The study was powered to detect a 2 min time difference in 
awakening between the groups. Using a group standard deviation of $2.7 \mathrm{~min}$ with a type 1 error of 0.05 and a power of 0.8 (derived from pilot data), we determined that each group required 33 patients. The Student's t-test was used to compare the demographic data, recovery times, and dose of phenylephrine. The sex ratio and patient movements were compared using Chisquare analysis or Fisher's exact test. All statistical tests were two tailed, and $\mathrm{P}<0.05$ was considered significant.

\section{Results}

The time to spontaneous ventilation, eye opening, extubation, and recovery of orientation were shorter in the sevoflurane than in the propofol group $(\mathrm{P}<0.05)$ (Table 2). The sevoflurane group required an average of $4.1 \pm 2.3 \mathrm{~min}$ for spontaneous ventilation, $6.7 \pm 2.9 \mathrm{~min}$ for eye opening, and $8.2 \pm 2.8 \mathrm{~min}$ for extubation. In contrast, the propofol group required $6.6 \pm 3.0$ min for spontaneous ventilation, $9.2 \pm 2.6 \mathrm{~min}$ for eye opening, and $10.4 \pm 2.8 \mathrm{~min}$ for extubation. Furthermore, the sevoflurane group required only $10.0 \pm 3.9 \mathrm{~min}$ for recovery of orientation, whereas the propofol group required $14.2 \pm 5.7 \mathrm{~min}$ to recover. The use of phenylephrine during the procedure was significantly greater in the propofol group $(\mathrm{P}<0.05)$. The sevoflurane group used $0.3 \pm 0.3 \mu \mathrm{g} / \mathrm{kg}$ of phenylephrine, whereas the propofol group used $0.7 \pm 0.9 \mu \mathrm{g} / \mathrm{kg}$. Alfentanil was not used during the procedure in either group. Three of 33 patients in the sevoflurane group showed movement during the procedure, whereas 10 out of 33 patients in the propofol group showed movement (Table 3).

\section{Discussion}

We found that the sevoflurane group showed a quicker recovery profile, lower incidence of movement during the procedure,

Table 2. Recovery Times ( $\mathrm{min})$

\begin{tabular}{lrrc}
\hline & $\begin{array}{c}\text { Sevoflurane } \\
(\mathrm{n}=33)\end{array}$ & $\begin{array}{c}\text { Propofol } \\
(\mathrm{n}=33)\end{array}$ & P value \\
\hline Spontaneous ventilation & $4.1 \pm 2.3$ & $6.6 \pm 3.0$ & $<0.001$ \\
Eye opening & $6.7 \pm 2.9$ & $9.2 \pm 2.6$ & 0.002 \\
Extubation & $8.2 \pm 2.8$ & $10.4 \pm 2.8$ & 0.01 \\
Orientation & $10.0 \pm 3.9$ & $14.2 \pm 5.7$ & $<0.001$ \\
\hline
\end{tabular}

Values are mean \pm SD.

Table 3. Use of Phenylephrine and Patient Movements during Procedure

\begin{tabular}{lcc}
\hline & $\begin{array}{c}\text { Sevoflurane } \\
(\mathrm{n}=33)\end{array}$ & $\begin{array}{c}\text { Propofol } \\
(\mathrm{n}=33)\end{array}$ \\
\hline $\begin{array}{l}\text { Dose of phenylephrine }(\mu \mathrm{g} / \mathrm{kg}) \\
\text { Patient movements }\end{array}$ & $\begin{array}{c}0.3 \pm 0.3 \\
9.1 \%(3 / 33)\end{array}$ & $\begin{array}{c}0.7 \pm 0.9 * \\
30.3 \%(10 / 33)^{*}\end{array}$ \\
\hline
\end{tabular}

Values are mean \pm SD or percentage of patients. $* \mathrm{P}<0.05$. and a lower phenylephrine requirement during the procedure compared with the propofol group.

All recovery times noted in this study were within the range of 5-9 min, which were consistent with those reported previously $[5,6]$. Previous studies comparing the recovery profiles after maintenance of anesthesia for neuroradiology with inhalation anesthetics or propofol $[5,6]$ showed that sevoflurane was associated with a more rapid recovery profile than propofol, whereas isoflurane and propofol showed similar recovery profiles from anesthesia. These studies used hemodynamic variables to titrate the depth of anesthesia. Although vital signs are good indicators of patient status during anesthesia, hemodynamic responses are caused by many factors and therefore cannot be used to assess the depth of anesthesia. Adequate anesthesia and hemodynamic responses do not always exhibit high correlations [11].

We used the BIS value as an index of the depth of anesthesia [12] because it is a better predictor of patient response than is hemodynamic status [10]. BIS monitoring can be used to predict whether patients will show movement in response to skin incisions when using propofol [13] or an inhalation agent for anesthesia [9]. A previous study using BIS monitoring as a guide to anesthetic depth showed that a large number of patients could be "fast-tracked" when anesthetic depth was monitored [10].

We used $0.6 \mathrm{mg} / \mathrm{kg}$ of rocuronium for induction and approximately $0.1-0.2 \mu \mathrm{g} / \mathrm{kg} / \mathrm{hr}$ of rocuronium for maintenance. Large doses of muscle relaxants may have facilitated prevention of patient movement. However, large doses may produce longlasting muscle paralysis, which may be undesirable in the clinical setting.

Typically, the amount of maintenance anesthetic is one-third that used for intubation. In this study, we used considerably less than the typical amount. The average ED95 of rocuronium is $382 \mu \mathrm{g} / \mathrm{kg}$ for Koreans [14]; however, we set the amount for maintenance in the range of $0.1-0.2 \mathrm{mg} / \mathrm{kg}$ because we wanted to use the least amount possible so that we could awaken the patient as soon as possible following the coil embolization procedure. Sevoflurane, in comparison with propofol, is known to increase the potency of rocuronium and prolong recovery time [15]. However, this recovery time is affected by the dose of rocuronium, as well as the MAC of the inhalation agent and its duration. We used small doses of rocuronium, and neostigmine was used for anesthesia reversal. As the anesthesia time was relatively short in this study, there were differences between types of anesthesia in the recovery time for adequate spontaneous respiration.

The lack of movement is critical to reduce the risk of perforation during the coiling of a cerebral aneurysm [3]. The definition for patient movement for this study included increased muscle tone detected by the surgical operator, but there were no cases where the patient displayed movement of the limbs, coughing, 
or bucking. The sevoflurane group showed a lower incidence of movement during the procedure. An element of pain is associated with distention and traction of the vessels. We assumed that sevoflurane might provide deeper anesthesia than propofol at comparable BIS values. It seems that the BIS thresholds are related to the combinations of anesthetic agents administered. Different combinations of anesthetic agents that achieved comparable BIS values did not show the same level of anesthesia $[10,16]$.

An argument might be made for avoiding the use of nitrous oxide because of the possibility of introducing air emboli into the cerebral circulation; however, no reports support this argument. Sevoflurane-nitrous oxide, as used in the present study, is currently the anesthetic combination of choice to induce rapid recovery. Nonetheless, nitrous oxide should be used with caution in interventional neuroradiology.

The propofol group used more phenylephrine than did the sevoflurane group. This result is in agreement with those of Ozkose et al. [17] who compared the total intravenous anesthesia (TIVA), sevoflurane, and isoflurane anesthesia in patients undergoing laminectomy and discectomy operations. The MAP decreased significantly after induction and during the maintenance of anesthesia in the TIVA group. During maintenance of anesthesia with propofol infusion, the systolic blood pressure was decreased to 20 to $30 \%$ less than the pre-anesthesia induction levels [18]. These decreases in blood pressure are often accompanied by corresponding changes in cardiac output and systemic vascular resistance.

Our study had several limitations. First, the BIS values remained either unchanged or even elevated during nitrous oxide anesthesia. However, despite potential problems, BIS monitoring proved predictive of movement when using propofol with nitrous oxide [13]. We attempted to obtain an equivalent depth of anesthesia by titrating the propofol or sevoflurane concentrations via the BIS monitor. A significant limitation is that BIS values may not be independent of the anesthetic agent used [19]. Nonetheless, BIS monitoring yields the best combination of sensitivity and specificity of all devices currently available to monitor the depth of anesthesia. A short duration of anesthesia (less than $90 \mathrm{~min}$ ) can affect the recovery profile rates due to the residual effects of the opioid or anesthetic agents used during induction [20]. Although recovery time differences of 2-5 min between the two groups were statistically significant, the clinical significance was uncertain.

In summary, compared with propofol, the use of sevoflurane for the maintenance of anesthesia during INR was associated with a more favorable profile in terms of the recovery from anesthesia, incidence of patient movement, and hemodynamic response.

\section{Acknowledgments}

This study is supported by grant to 02-2010-029 from the SNUBH Research Fund.

\section{References}

1. Choi SS, Kim JS, Park IK, Lee G, Hahm KD. Changes in the bispectral index and cerebral oxygen saturation during neuroendovascular intervention under general anesthesia. Korean J Anesthesiol 2012; 62: 98-100.

2. Kim JE, Park JH, Lee SH, Lee Y. Neurogenic pulmonary edema following intracranial coil embolization for subarachnoid hemorrhage-A case report. Korean J Anesthesiol 2012; 63: 368-71.

3. Varma MK, Price K, Jayakrishnan V, Manickam B, Kessell G. Anaesthetic considerations for interventional neuroradiology. Br J Anaesth 2007; 99: 75-85

4. Han SJ, Lee JH, Jang IS, Kim HT, Kwon YE. Acute cerebral infarction due to thrombus formation during GDC embolization for the treatment of intracranial aneurysm-A case report. Korean J Anesthesiol 2008; 55: 254-8.

5. Münte S, Münte TF, Kuche H, Osthaus A, Herzog T, Heine J, et al. General anesthesia for interventional neuroradiology: propofol versus isoflurane. J Clin Anesth 2001; 13: 186-92.

6. Castagnini HE, van Eijs F, Salevsky FC, Nathanson MH. Sevoflurane for interventional neuroradiology procedures is associated with more rapid early recovery than propofol. Can J Anaesth 2004; 51: 486-91.

7. Hug CC Jr. Does opioid "anesthesia" exist? Anesthesiology 1990; 73: 1-4.

8. Song D, Joshi GP, White PF. Titration of volatile anesthetics using bispectral index facilitates recovery after ambulatory anesthesia. Anesthesiology 1997; 87: 842-8.

9. Gan TJ, Glass PS, Windsor A, Payne F, Rosow C, Sebel P, et al. Bispectral index monitoring allows faster emergence and improved recovery from propofol, alfentanil, and nitrous oxide anesthesia. BIS Utility Study Group. Anesthesiology 1997; 87: 808-15.

10. Vernon JM, Lang E, Sebel PS, Manberg P. Prediction of movement using bispectral electroencephalographic analysis during propofol/ alfentanil or isoflurane/alfentanil anesthesia. Anesth Analg 1995; 80: 780-5.

11. Ghouri AF, Monk TG, White PF. Electroencephalogram spectral edge frequency, lower esophageal contractility, and autonomic responsiveness during general anesthesia. J Clin Monit 1993; 9: 176-85. 
12. Eger EI 2nd, Saidman LJ, Brandstater B. Minimum alveolar anesthetic concentration: a standard of anesthetic potency. Anesthesiology 1965; 26: 756-63.

13. Leslie K, Sessler DI, Smith WD, Larson MD, Ozaki M, Blanchard D, et al. Prediction of movement during propofol/nitrous oxide anesthesia. Performance of concentration, electroencephalographic, pupillary, and hemodynamic indicators. Anesthesiology 1996; 84: 52-63.

14. Shin HS, Lee SI, Lee JH, Lee SC. Effective dose of rocuronium in Koreans. Korean J Anesthesiol 2005; 48: 367-74.

15. Bock M, Klippel K, Nitsche B, Bach A, Martin E, Motsch J. Rocuronium potency and recovery characteristics during steady-state desflurane, sevoflurane, isoflurane or propofol anaesthesia. Br J Anaesth 2000; 84: 43-7.

16. Mi WD, Sakai T, Takahashi S, Matsuki A. Haemodynamic and electroencephalograph responses to intubation during induction with propofol or propofol/fentanyl. Can J Anaesth 1998; 45: 19-22.

17. Ozkose Z, Ercan B, Unal Y, Yardim S, Kaymaz M, Dogulu F, et al. Inhalation versus total intravenous anesthesia for lumbar disc herniation: comparison of hemodynamic effects, recovery characteristics, and cost. J Neurosurg Anesthesiol 2001; 13: 296-302.

18. Ebert TJ, Muzi M. Propofol and autonomic reflex function in humans. Anesth Analg 1994; 78: 369-75.

19. Mi WD, Sakai T, Singh H, Kudo T, Kudo M, Matsuki A. Hypnotic endpoints vs. the bispectral index, $95 \%$ spectral edge frequency and median frequency during propofol infusion with or without fentanyl. Eur J Anaesthesiol 1999; 16: 47-52.

20. Ebert TJ, Robinson BJ, Uhrich TD, Mackenthun A, Pichotta PJ. Recovery from sevoflurane anesthesia: a comparison to isoflurane and propofol anesthesia. Anesthesiology 1998; 89: 1524-31. 